\title{
Solar Energy Conversion by Dye-Sensitized Photovoltaic Cells Using High Surface Area Mesoporous Carbon Counter Electrode
}

\author{
Pavuluri Srinivasu, ${ }^{1}$ Surya Prakash Singh, ${ }^{2}$ Ashraful Islam, ${ }^{2,3}$ and Liyuan Han ${ }^{2}$ \\ ${ }^{1}$ International Center for Young Scientists, International Center for Materials Nanoarchitectonics, \\ National Institute for Materials Science, 1-1 Namiki, Tsukuba, Ibaraki 305-0044, Japan \\ ${ }^{2}$ Photovoltaic Materials Unit, National Institute for Materials Science, 1-2-1 Sengen, Tsukuba, Ibaraki 305-0047, Japan \\ ${ }^{3}$ Center of Excellence for Research in Engineering Materials (CEREM), College of Engineering, King Saud University, \\ Riyadh 11421, Saudi Arabia
}

Correspondence should be addressed to Pavuluri Srinivasu, pavuluri.srini@gmail.com

Received 16 May 2011; Accepted 24 July 2011

Academic Editor: Idriss M. Bedja

Copyright (C) 2011 Pavuluri Srinivasu et al. This is an open access article distributed under the Creative Commons Attribution License, which permits unrestricted use, distribution, and reproduction in any medium, provided the original work is properly cited.

\begin{abstract}
Development of new counter electrode materials is vital for commercialization of efficient dye-sensitized solar cells (DSCs) process. Research on DSCs has been focused mainly on using platinum as counter electrode, which makes them expensive. In this paper, we report DSCs fabricated with high surface area mesoporous carbon thin film with uniform spherical particles as counter electrode. An overall light-to-electricity efficiency as high as $7.6 \%$ has been achieved under illumination of air mass (AM) 1.5 sunlight $\left(100 \mathrm{~mW} / \mathrm{cm}^{2}\right)$. In comparison with activated carbon, high surface area mesoporous carbon shows superior performance. Our results show that mesoporous carbon with high specific surface area and uniform pore size distribution proved to be better efficient electrode material for DSCs.
\end{abstract}

\section{Introduction}

Environmental concerns and global energy demand have triggered the interest in development of renewable energy especially solar energy. Conventional silicon-based solar cells are large-scale, single-junction devices, and very high percentage of photovoltaic production comes from these solar cells $[1,2]$. However, cost of these solar cells made them not economical compared with other power-generating methods. In recent years, DSCs have attracted a great deal of attention due to its simple fabrication and low production cost. DSCs are composed of porous nanostructured oxide film with adsorbed dye molecules as a dye-sensitized anode, an electrolyte containing iodide/triiodide redox couple, and a platinized fluorine-doped tin oxide (FTO) glass as the counter electrode [3-5]. For further reduction of production cost of DSCs, development of new electrode material to replace platinum counter electrode is highly desirable. Mesoporous carbon with very high surface area and uniform pore size distribution has emerged to be the best candidate in this respect. In addition, porous carbons have attracted much attention due to their potential applications in catalysis, adsorption, storage of natural gas, separation process, and electric double-layer capacitors [6-10]. Several different methods have been developed to synthesize mesoporous carbons. Among them, template synthesis method [11, 12] has been extensively used since the obtained material possesses uniform and interconnected pores. This synthetic technique involves impregnation of silica templates with an appropriate carbon source, carbonization of carbon precursor, and subsequent removal of silica. After the discovery of ordered mesoporous carbon materials by Ryoo et al. using mesoporous silica as a template and sucrose as a carbon source there is a growing interest in the synthesis of mesoporous carbons [11].

Recently, Srinivasu et al. have demonstrated twodimensional hexagonal large mesoporous carbon as metalfree counter electrode for solar cells [13]. Mesoporous carbon materials with uniform sphere particles have been used for various catalytic applications. However, the influence 
of porous carbon spheres on DSCs performance has not been investigated thoroughly yet. And mesoporous carbon material with uniform sphere particles has also not been used in the open literature as a counter electrode in achieving high efficiency in DSCs. In this paper, we report the fabrication of high surface area mesoporous carbon film with uniform sphere particles as a counter electrode for DSCs.

\section{Experimental}

2.1. Preparation of Mesoporous Carbon Electrode. The high surface area mesoporous carbon was prepared using mesoporous silica, MCM48 as a hard template, and sucrose as a carbon source. In a typical synthesis of mesoporous carbon, $1 \mathrm{~g}$ of template was added to a solution obtained by dissolving $1.25 \mathrm{~g}$ of sucrose and $2.5 \mathrm{~g}$ of water and keeping the mixture in an oven for $6 \mathrm{~h}$ at $100^{\circ} \mathrm{C}$. Subsequently, the oven temperature was raised to $160^{\circ} \mathrm{C}$ for another $6 \mathrm{~h}$. In order to obtain fully polymerized and carbonized sucrose inside the pores of silica template, $0.8 \mathrm{~g}$ of sucrose, $0.09 \mathrm{~g}$ of $\mathrm{H}_{2} \mathrm{SO}_{4}$, and $2.5 \mathrm{~g}$ of water were again added to the pretreated sample and the mixture was again subjected to thermal treatment as described above. The template-polymer composites were then pyrolyzed in a nitrogen flow at $900^{\circ} \mathrm{C}$ and kept under these conditions for $6 \mathrm{~h}$ to carbonize the polymer. The mesoporous carbon was recovered after dissolution of the silica framework. The final mesoporous carbon material with uniform sphere (MCS) was used to prepare a film on FTO glass using doctor-blade technique $[14,15]$, which was ultrasonically cleaned in ethanol prior to use.

Powder X-ray diffraction patterns were obtained through a Rigaku diffractometer using $\mathrm{CuK} \alpha(\lambda=0.154 \mathrm{~nm})$ radiation. $\mathrm{N}_{2}$ adsorption-desorption isotherms are measured at $77 \mathrm{~K}$ on a Micromeritics Tristar II 3020 adsorption analyzer. Before the adsorption measurements, all samples are outgassed at $250^{\circ} \mathrm{C}$ in the port of the adsorption analyzer. The position of the maximum on pore size distribution is referred to as the pore diameter, which was calculated from adsorption branches by Barret-Joyner-Halenda (BJH) method. The HRTEM images are obtained with JEOL JEM2100F. Hitachi S-4800 HR-FESEM is used to observe the morphology of the material.

2.2. Fabrication of Dye-Sensitized Solar Cell. A nanocrystalline $\mathrm{TiO}_{2}$ photoelectrode of $20 \mu \mathrm{m}$ thickness (area: $0.25 \mathrm{~cm}^{2}$ ) was prepared by screen printing on conducting glass as previously described [16]. The films were further treated with $0.05 \mathrm{M} \mathrm{TiCl}_{4}$ and $0.1 \mathrm{M} \mathrm{HCl}$ aqueous solutions before examination [17]. Coating of the $\mathrm{TiO}_{2}$ film was carried out by immersing for $45 \mathrm{~h}$ in a sensitizer solution (N719) of $3 \times 10^{-4} \mathrm{M}$ acetonitrile/tert-butyl alcohol (1/1, $v / v)$ solution. Deoxychloric acid $(20 \mathrm{mM})$ was added to the dye solution as a coadsorbent to prevent aggregation of dye molecules $[18,19]$. Photovoltaic measurements were performed in a two-electrode sandwich cell configuration. The dye-deposited $\mathrm{TiO}_{2}$ film and a mesoporous carbon on conductive glass were used as the working electrode and the counter electrode, respectively. The two electrodes

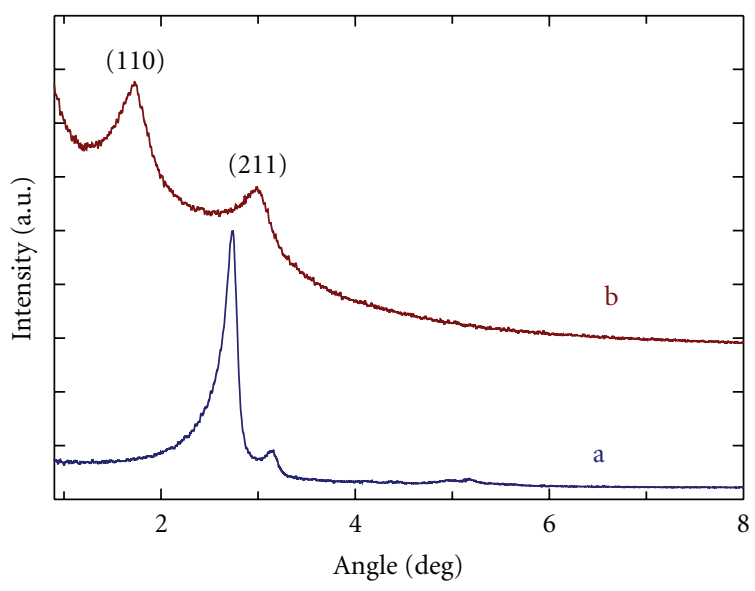

FIGURE 1: Powder XRD patterns of (a) MCM48 and (b) MCS material.

TABLE 1: Textural parameters of MCS material.

\begin{tabular}{lccc}
\hline Sample & $\mathrm{A}_{\mathrm{BET}} / \mathrm{m}^{2} \cdot \mathrm{g}^{-1}$ & $\mathrm{~V}_{p}\left(\mathrm{~cm}^{3} / \mathrm{g}\right)$ & $\begin{array}{c}\mathrm{dp}, \mathrm{BJH}(\mathrm{nm}) \\
\text { adsorption }\end{array}$ \\
\hline MCM48 & 1182 & 1.28 & 2.5 \\
MCS & 1594 & 1.20 & 2.3 \\
\hline
\end{tabular}

were separated by a surlyn spacer $(40 \mu \mathrm{m})$ and sealed by heating the polymer frame. The electrolyte was composed of $0.6 \mathrm{M}$ dimethylpropyl-imidazolium iodide (DMPII), $0.05 \mathrm{M}$ $\mathrm{I}_{2}$, TBP $0.5 \mathrm{M}$, and $0.1 \mathrm{M}$ LiI in acetonitrile.

\section{Results and Discussion}

Powder XRD patterns of mesoporous carbon spheres (MCSs) prepared using sucrose as a carbon source is shown in Figure 1. The sample exhibits three reflections on the region $2 \theta=1.5-3.5^{\circ}$ which are indexed to (110), (211), and (220) reflections of the cubic space group $I 4_{1} 32$. It is interesting to note that periodic structure of MCS material is different from the template MCM48, which is because the carbon networks formed from bicontinuous two mesochannels systems of MCM48 structure are not interconnected. The two channel systems of MCM48 can undergo mutual displacement of their positions upon removal of silica template. The removal of silica wall causes the appearance of new (110) reflection in XRD, which indicates that the Ia3d structure of MCM48 transformed systematically to cubic $I 4_{1} 32$ [11]. Further, textural characterization information is obtained using nitrogen adsorption and desorption isotherm. The textural properties of MCS and pure siliceous MCM48 samples are shown in Table 1. The adsorption and desorption isotherm of MCS sample are well-pronounced capillary condensation step similar to that of mesoporous silica MCM48 indicating high degree of uniform mesoporous material (Figure 2). The specific surface area is calculated from standard BrunauerEmmett-Teller (BET) method. The isotherm also reveals that the MCS has high BET specific surface area of $1594 \mathrm{~m}^{2} / \mathrm{g}$, 


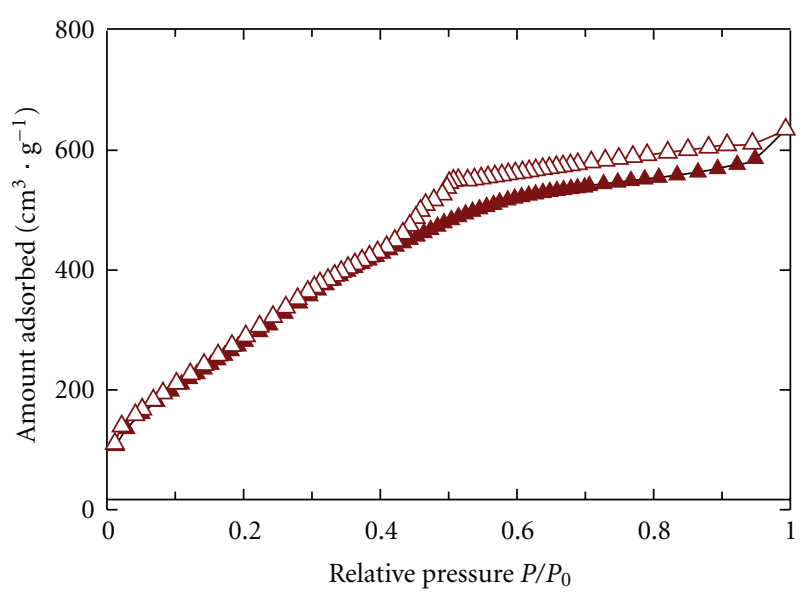

FIGURE 2: Nitrogen adsorption-desorption isotherms of MCS material ( $\boldsymbol{\Delta}$-adsorption, $\Delta$-desorption).

which is higher than that of MCM48 template and total pore volume of MCS material is $1.2 \mathrm{~cm}^{3} / \mathrm{g}$. The pore size of materials is calculated from Barrett-Joyner-Halenda $(\mathrm{BJH})$ method. Typically MCS material has pore size distribution at $2.3 \mathrm{~nm}$ from adsorption branch of nitrogen isotherm. In general, replication process gives carbon with pore size equal to wall thickness of template; however MCS pore size is almost double the wall thickness of template MCM48, which is due to structural transformation of MCS material attributed to strain in the carbon framework upon removal of the template. High-resolution scanning electron microscopy (HR-SEM) image of mesoporous carbon MCS sample is shown in Figure 3(a). The MCS material retains the morphology of template MCM48 with regular spherical morphology of partice size in the range of 0.06 to $0.2 \mu \mathrm{m}$. The high-resolution transmission electron microscopy (HRTEM) image for the MCS material is shown in Figure 3(b). The TEM image shows that regular array of holes separated by walls. The MCS material gave regular pore structure like MCM-48 without carbon deposition on the external surface.

The photocurrent density and voltage spectra of cells were measured using N719 dye under illumination of air mass (AM) 1.5 sunlight. Figure 4 shows the photocurrent density-photovoltage performance for DSCs based on MCS counter electrode. The short-circuit current $\left(J_{s c}\right)$, the open-circuit voltage $\left(V_{\mathrm{oc}}\right)$, and the fill factor $(\mathrm{FF})$ are $15.26 \mathrm{~mA} / \mathrm{cm}^{2}, 0.74 \mathrm{~V}$, and $0.68 \%$, respectively. The overall conversion efficiency $(\eta)$ of $7.64 \%$ obtained for MCS electrode is superior to $1.44 \%$ efficiency of activated charcoal.

\section{Conclusions}

In summary, we have successfully fabricated mesoporous carbon thin film with uniform sphere particles as a counter electrode for dye-sensitized solar cells. The mesoporous carbon spheres exhibited specific surface area of $1594 \mathrm{~m}^{2} / \mathrm{g}$ and ordered pore structure with pore size of $2.3 \mathrm{~nm}$. We have demonstrated that high specific surface area and ordered pore structure of mesoporous carbon spheres favor in the

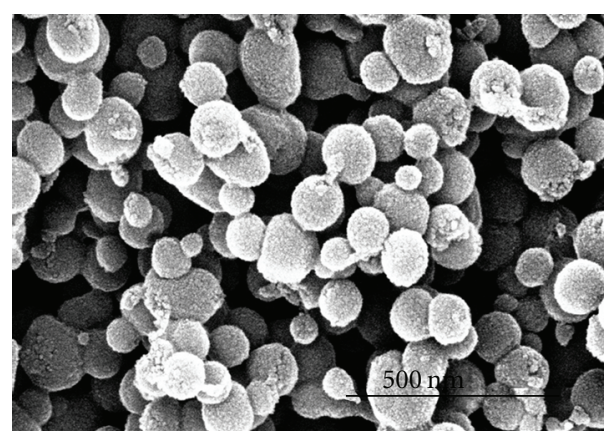

(a)

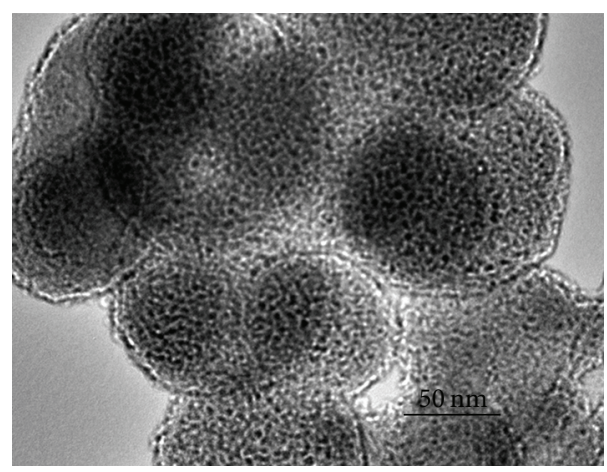

(b)

FIgURE 3: (a) HRSEM and (b) HRTEM images of MCS material.

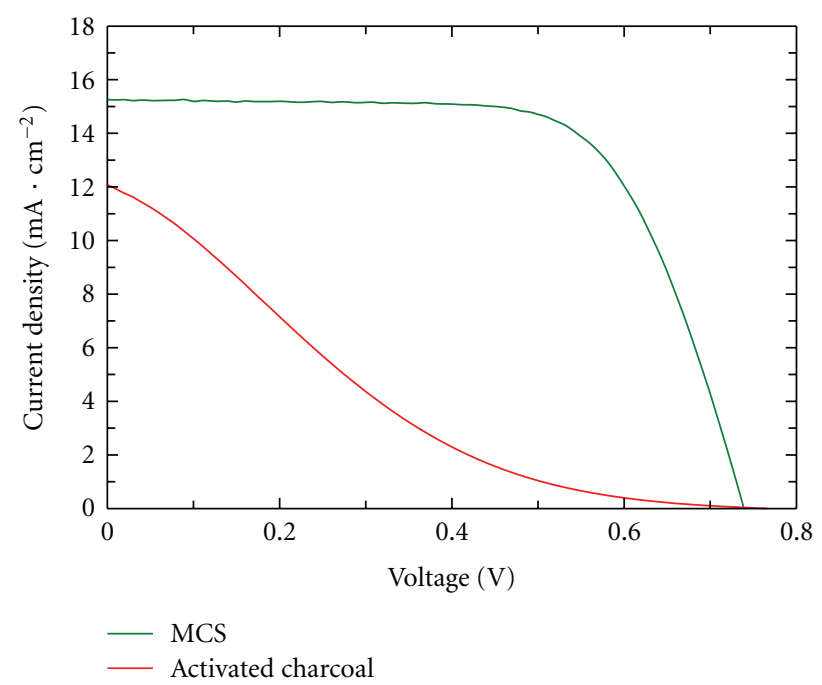

Figure 4: Photocurrent-voltage characteristics of dye-sensitized solar cells of MCS and activated charcoal materials.

superior performance for dye-sensitized solar cells than that of activated charcoal. The new electrode material in turn leads to many future studies on their advanced applications.

\section{Acknowledgments}

The author P. Srinivasu thanks the International Center for Young Scientists (ICYS) and International Center for 
Materials Nanoarchitectonics (MANA) at National Institute for Materials Science, Tsukuba, Japan for financial support.

\section{References}

[1] M. K. Nazeeruddin, A. Kay, I. Rodicio et al., "Conversion of light to electricity by cis- $\mathrm{X}_{2}$ bis $\left(2,2^{\prime}\right.$-bipyridyl- $4,4^{\prime}$-dicarboxylate)ruthenium(II) charge-transfer sensitizers $\left(\mathrm{X}=\mathrm{Cl}^{-}\right.$, $\mathrm{Br}^{-}, \mathrm{I}^{-}, \mathrm{CN}^{-}$, and $\mathrm{SCN}^{-}$) on nanocrystalline $\mathrm{TiO}_{2}$ electrodes," Journal of the American Chemical Society, vol. 115, no. 14, pp. 6382-6390, 1993.

[2] Y. Chiba, A. Islam, Y. Watanabe, R. Komiya, N. Koide, and L. Han, "Dye-sensitized solar cells with conversion efficiency of 11.1\%," Japanese Journal of Applied Physics, vol. 45, no. 24-28, pp. L638-L640, 2006.

[3] A. Hagfeld and M. Grätzel, "Light-induced redox reactions in nanocrystalline systems," Chemical Reviews, vol. 95, no. 1, pp. 49-68, 1995.

[4] M. Law, L. E. Greene, J. C. Johnson, R. Saykally, and P. Yang, "Nanowire dye-sensitized solar cells," Nature Materials, vol. 4, no. 6, pp. 455-459, 2005.

[5] E. M. Kaidashev, M. Lorenz, H. Von Wenckstern et al., "High electron mobility of epitaxial $\mathrm{ZnO}$ thin films on $c$-plane sapphire grown by multistep pulsed-laser deposition," Applied Physics Letters, vol. 82, no. 22, pp. 3901-3903, 2003.

[6] S. H. Joo, S. J. Choi, I. Oh et al., "Ordered nanoporous arrays of carbon supporting high dispersions of platinum nanoparticles," Nature, vol. 412, no. 6843, pp. 169-172, 2001.

[7] L. Schlapbach and A. Züttel, "Hydrogen-storage materials for mobile applications," Nature, vol. 414, no. 6861, pp. 353-358, 2001.

[8] J. Lee, S. Yoon, T. Hyeon, S. M. Oh, and K. B. Kim, "Synthesis of a new mesoporous carbon and its application to electrochemical double-layer capacitors," Chemical Communications, no. 21, pp. 2177-2178, 1999.

[9] K. Kaneko and J. Imai, "Adsorption of $\mathrm{NO}_{2}$ on activated carbon fibers," Carbon, vol. 27, no. 6, pp. 954-955, 1989.

[10] P. Srinivasu, "Investigation on the textural properties tuning of ordered mesoporous carbons with an excellent electrochemical performance," Advances in OptoElectronics, vol. 2011, Article ID 615164, 2011.

[11] R. Ryoo, S. H. Joo, and S. Jun, "Synthesis of highly ordered carbon molecular sieves via template-mediated structural transformation," Journal of Physical Chemistry B, vol. 103, no. 37, pp. 7745-7746, 1999.

[12] H. Wei, Y. Lv, L. Han, B. Tu, and D. Zhao, "Facile synthesis of transparent mesostructured composites and corresponding crack-free mesoporous carbon/silica monoliths," Chemistry of Materials, vol. 23, no. 9, pp. 2353-2360, 2011.

[13] P. Srinivasu, S. P. Singh, A. Islam, and L. Han, "Metalfree counter electrode for efficient dye-sensitized solar cells through high surface area and large-porous carbon," International Journal of Photoenergy, vol. 2011, Article ID 617439, 2011.

[14] I. M. Arabatzis, T. Stergiopoulos, M. C. Bernard, D. Labou, S. G. Neophytides, and P. Falaras, "Silver-modified titanium dioxide thin films for efficient photodegradation of methyl orange," Applied Catalysis B, vol. 42, no. 2, pp. 187-201, 2003.

[15] R. E. Mistler, "Tape casting. The basic process for meeting the needs of the electronics industry," American Ceramic Society Bulletin, vol. 69, no. 6, pp. 1022-1026, 1990.
[16] M. K. Nazeeruddin, P. Péchy, T. Renouard et al., "Engineering of efficient panchromatic sensitizers for nanocrystalline $\mathrm{TiO}_{2}-$ based solar cells," Journal of the American Chemical Society, vol. 123, no. 8, pp. 1613-1624, 2001.

[17] Z. S. Wang, T. Yamaguchi, H. Sugihara, and H. Arakawa, "Significant efficiency improvement of the black dye-sensitized solar cell through protonation of $\mathrm{TiO}_{2}$ films," Langmuir, vol. 21, no. 10, pp. 4272-4276, 2005.

[18] M. Ikeda, N. Koide, L. Han, A. Sasahara, and H. Onishi, "Scanning tunneling microscopy study of black dye and deoxycholic acid adsorbed on a rutile $\mathrm{TiO}_{2}(110)$," Langmuir, vol. 24, no. 15, pp. 8056-8060, 2008.

[19] Z. S. Wang, Y. Cui, Y. Dan-oh, C. Kasada, A. Shinpo, and K. Hara, "Thiophene-functionalized coumarin dye for efficient dye-sensitized solar cells: electron lifetime improved by coadsorption of deoxycholic acid," Journal of Physical Chemistry C, vol. 111, no. 19, pp. 7224-7230, 2007. 

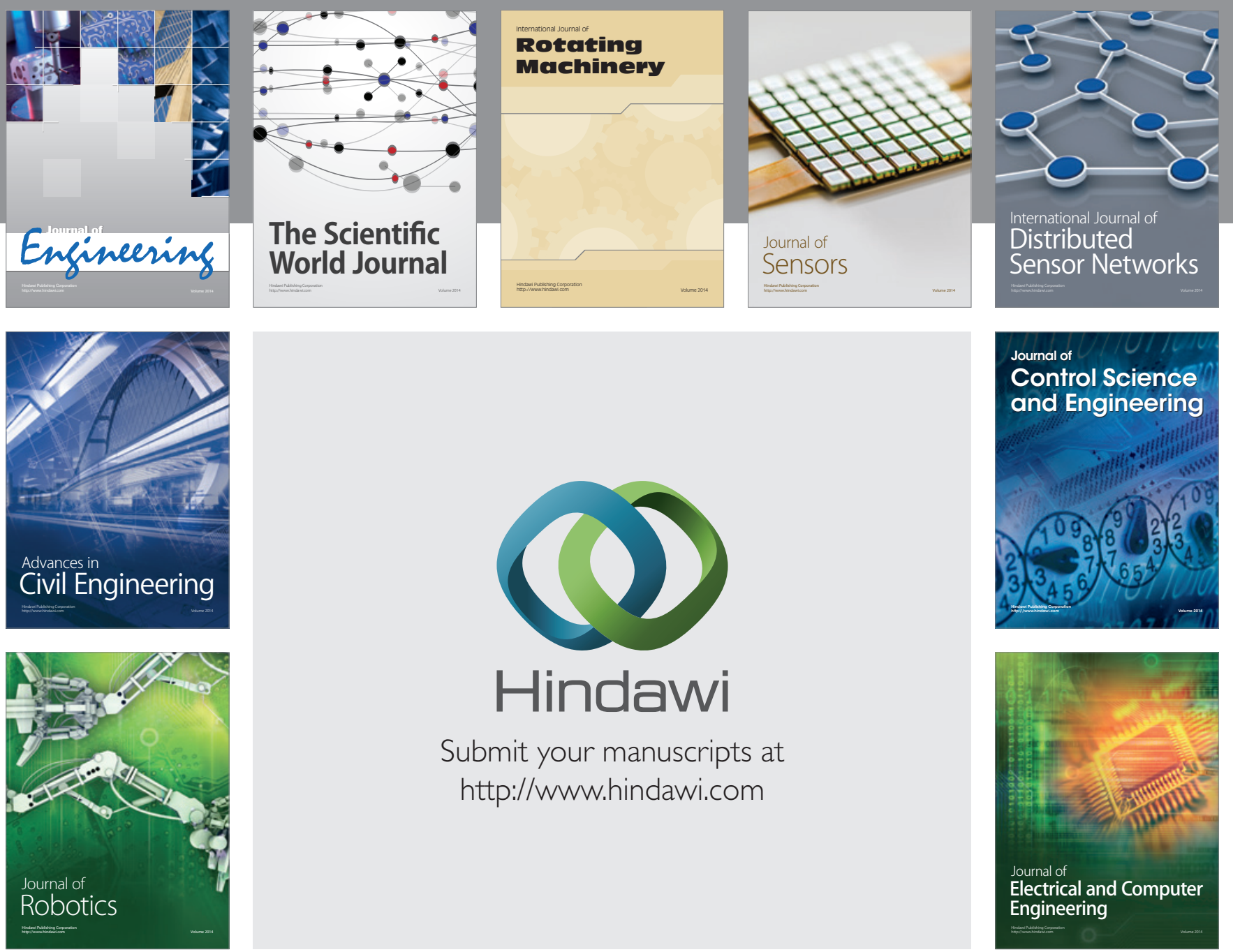

Submit your manuscripts at

http://www.hindawi.com
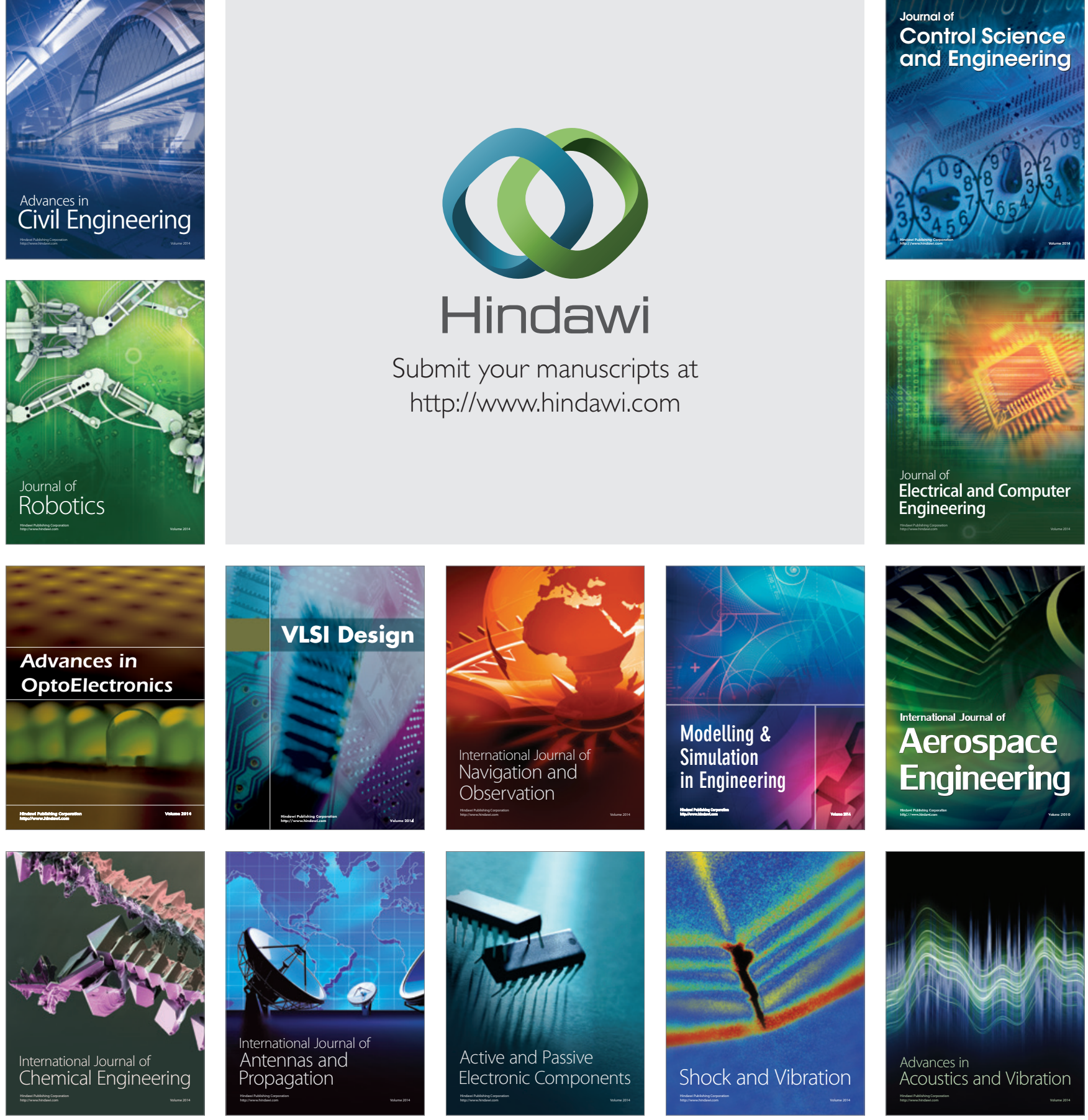